\title{
A Case Based Approach to Assess Waiting Time Prediction at an Intensive Care Unity
}

\author{
Ana Quintas, Henrique Vicente, Paulo Novais, António Abelha, \\ M. Filipe Santos, José Machado and José Neves
}

\begin{abstract}
Waiting time at an intensive care unity stands for a key feature in the assessment of healthcare quality. Nevertheless, its estimation is a difficult task, not only due to the different factors with intricate relations among them, but also with respect to the available data, which may be incomplete, self-contradictory or even unknown. However, its prediction not only improves the patients' satisfaction but also enhance the quality of the healthcare being provided. To fulfill this goal, this work aims at the development of a decision support system that allows one to predict how long a patient should remain at an emergency unit, having into consideration all the remarks that were just stated above. It is built on top of a Logic Programming approach to knowledge representation and reasoning, complemented with a Case Base approach to computing.
\end{abstract}

\footnotetext{
A. Quintas

Departamento de Informática, Universidade do Minho, Braga, Portugal

e-mail: asoquintas@gmail.com

H. Vicente

Departamento de Química, Escola de Ciências e Tecnologia, Universidade de Évora, Évora, Portugal

e-mail: hvicente@uevora.pt

H. Vicente $\cdot$ P. Novais · A. Abelha · J. Machado · J. Neves ( $\square)$

Centro Algoritmi, Universidade do Minho, Braga, Portugal

e-mail: jneves@di.uminho.pt

P. Novais

e-mail: pjon@di.uminho.pt
A. Abelha
e-mail: abelha@di.uminho.pt
J. Machado
e-mail: jmac@di.uminho.pt

M. Filipe Santos

Centro Algoritmi, Universidade do Minho, Guimarães, Portugal

e-mail: mfs@dsi.uminho.pt 
Keywords Waiting time - Intensive care unitlogic programming - Logic programming - Knowledge representation and reasoning - Case-based reasoning • Similarity analysis 